\title{
Effect of Muscle Energy Techniques V/S Active Range of Motion Exercises on Shoulder Function Post Modified Radical Neck Dissection in patients with Head and Neck Cancer - A Randomized Clinical Trial
}

\author{
Anmol Thomas', Cherishma D'Silva ${ }^{2 *}$, Leah Mohandas², Sudeep M J Pais², \\ Stephen Rajan Samuel ${ }^{3}$
}

\begin{abstract}
Purpose: Shoulder and cervical pain, reduced mobility and disability are some of the major complications associated with surgeries of head and neck cancers affecting several domains of quality of life. In the present study we aimed to compare the effectiveness of Muscle Ener-gy Techniques (METS) and Active Range of Motion Exercises in reducing pain, improving shoulder mobility and function in patients post Modified Radical Neck Dissection (MRND). Methods: Forty eight subjects were randomly assigned to two groups. Group A received active range of motion (AROM) exercises and group B received Muscle energy techniques (METS). Both the groups were treated for a period of 10 consecutive days starting from the 3rd to 5th postoperative day. Data was collected on the 1st and 10th day of intervention. Results: Both groups showed highly significant improvements in shoulder range of motion, decrease in pain and better Global Rating Change cores(GRCS) ( $\mathrm{p}=0.005)$. GRCS and shoul-der abduction showed significant improvement in group B when compared to group A, sug-gesting better clinical outcomes in those treated with Muscle Energy Techniques. Conclusion: This study showed that both METs and AROM exercises were effective in im-proving shoulder range of motion, function and reducing pain in patients post MRND but-Muscle Energy Techniques were more effective when compared to AROM exercises.
\end{abstract}

Keywords: Modified radical neck dissection- radical neck dissection- shoulder function- muscle energy techniques

Asian Pac J Cancer Prev, 21 (8), 2389-2393

\section{Introduction}

Over 2 million cases of head and neck cancer occur each year in India. Head and neck cancer accounts for $30 \%$ of all cancers in India and nearly 50\% deaths occur within 12 months of diagnosis. Nearly $50 \%$ of the survivors are left disabled due to surgery and chemotherapy (Guru et al., 2012).

Neck dissection followed by chemotherapy and radiotherapy is the treatment of choice for head and neck cancer (HNC) (Robbinsons et al.,1991) Radical neck dissection (RND) is one of the major treatment procedures used in the management of head and neck cancers but is known to have higher morbidity, greater post-operative complications and loss of function. It involves complete sacrifice of the sensory branches of the cervical plexus, and the $\mathrm{C} 2, \mathrm{C} 3$ and $\mathrm{C} 4$ branches that supply sternocleidomastoid and trapezius. This in turn leads to disfig-urement, which includes asymmetry of the mouth and facial oedema, loss of normal shoulder contour, abnormal scapular prominence and hollowing of the scapular region. Patients also complain of shoulder pain, sensory disturbances, and reduced strength of the arm and diffi-culty with their activities of daily living. To minimize these post-operative risks and compli-cations new and modified techniques such as selective neck dissection and modified radical neck dissection, have come into practice (MacComb,1968; Ewing and Martin,1952). Modified radical neck dissection (MRND), allows preservation of the spinal accessory nerve. In this procedure, some of the important structures are spared. MRND reduces the post-operative complications and disability to the neck and shoulder when compared to classic RND proce-dure. Even though spinal accessory nerve (SAN) is spared in MRND, there still persists high incidence of shoulder complaints and disability post-surgery. This is because preservation of SAN does not completely eliminate the risk of post-operative musculoskeletal complications. The

${ }^{1}$ MPT Father Muller Medical College Hospital, Mangalore, Karnataka, India. ${ }^{2}$ Department of Physiotherapy, Father Muller Medical College Hospital, Mangalore, Karnataka, India. ${ }^{3}$ Department of Physiotherapy, Kasturba Medical College Mangalore, Karnataka, India.*For Correspondence: cheri8585@gmail.com 
incidence of shoulder complaints post RND surgery ranges from $47 \%$ to $100 \%$, and it ranges from $18 \%$ to $77 \%$ post MRND (Wilgen et al., 2003; Wilgen et al., 2004; Ganne et al., 2017) EMG studies following MRND showed that the amplitude and the response area of evoked potential were significantly lower when compared to the non-operated side. Also the development of secondary complications such as joint fibrosis and secondary adhesive cap-sulitis can lead to reduced mobility at the shoulder. A recent study also showed that male patients with $\mathrm{HNC}$ are at risk of developing sarcopenia and its related adverse ef-fects (Chauhan et al., 2020) These impairments have a severe impact on the quality of life of these patients(Gang et al., 2017; Chepeha et al., 2002 ; Cheng et al., 2000; Luan et al., 2006).

Studies show that various physiotherapy modalities such as interferential therapy and faradic stimulation and techniques such as passive range of motion exercises, active assisted range of motion exercises, active range of motion exercises, strengthening exercises, PNF techniques, progressive resistance training (PRT), stretching exercises are known to prevent postoperative complications and also improve the shoulder range of motion there by reducing shoulder stiffness and tightness caused due to various causes (Baggi et al., 2014; Lauchlan et al., 2011; Ginn and Cohen, 2005; Reeve et al., 2010)

Muscle energy techniques (METS) are a set of soft tissue manipulation methods which include directed and controlled, isometric and/or isotonic contractions, which are performed by the patients. These techniques are aimed at reducing pain and improving musculoskeletal function (Bathia et al., 2016) Although both Active ROM exercises and MET exercises are known to improve shoulder function and pain post surgically, no studies were previously conducted to compare their effectiveness in this population. The aim of this study was to compare the effectiveness of these two treatment procedures and to determine which tech-nique would be effective in improving shoulder range of motion and reducing pain post MRND.

\section{Materials and Methods}

\section{Methodology}

Ethical Clearance was obtained from the Institutional Ethical Committee. Forty eight subjects with a mean age of 53.64 years, who underwent MRND surgery were included. Patients will-ing to participate were explained about the study in their own language and written informed consent was obtained. Patients with Head and Neck Cancers who underwent recent MRND surgery, aged between $30-65$ years were included in the study. Patients were excluded if they had any 1) recent fracture or surgery to the shoulder 2) rotator cuff injury 3 ) recurrent shoul-der dislocation. Subjects were then randomly allocated into two groups using concealed enve-lope method (Figure 1).

The Baseline Measurements of ROM and Pain intensity were assessed and documented prior to the onset of treatment. The treatment began from $3^{\text {rd }}$ to $5^{\text {th }}$ postoperative day. Shoulder range of motion was measured using Universal goniometer and pain intensity was measured using numeric pain rating scale. Global rating of change scale (GRCS)which determines the effect of the intervention is a numerical rating scale, scoring between -5 ( very much worse) to +5 (completely recovered), and 0 being unchanged. Group A received Active range of motion exercises (AROM) which included Pendulum exercises in standing position, active assisted ROM in supine position (which was then progressed to active exercises), cross body adduction in supine position and wall climbing or finger ladder exercises in standing posi-tion. Subject continued taking the arm up until the shoulder had maximum tolerable stretch, and was held at that position for 30 seconds. All exercises were given for 2 sets of 10 repetitions. Two subjects from Group A dropped out of the study as they developed post operative complications on the 4th post operative day.

Group B received MET exercises which included post isometric relaxation techniques for shoulder flexion, abduction and internal rotation. Patient position was supine lying. They were asked to contract using $20 \%$ of their muscle force. The contraction was held for 7-10 seconds. Therapist then moved the shoulder passively into the range where a new restriction barrier was found. Pain, range of motion and GRCS were reassessed post 10 days of inter-vention.

\section{Results}

A total of forty eight subjects were recruited for this study based on the inclusion and exclu-sion criteria. Two subjects from group A dropped out of the study as they underwent flap re-suturing and drain fixation during the intervention period. Following which results of forty-six subjects were analysed. Group A had a total of 21 subjects (15 males and 6 females). Group B had 25 subjects (22 males and 3 females). All subjects were similar at baseline with respect to age and the mean age of all subjects in group A was 52.90 (SD) and group B was 53.64 (SD) .NPRS at baseline showed a mean score of $7.10 \pm 0.83$ and $7.24 \pm 0.59$ in group A and group B respectively. Baseline scores of GRCS was $-3.00 \pm 0.77$ in Group A and and $-3.60 \pm 0.50$ in Group B. The baseline measures for shoulder abduction range of motion showed a mean value of $96.76 \pm 19.66$ in group A and $92.16 \pm 10.61$ in group B, internal rota-tion of $53.71 \pm 7.54$ in group A and $54.16 \pm$ 7.25 in group $B$, external rotation of $52.76 \pm 8.97$ in group A and 56.88 \pm 6.16 in group B and flexion of $124.57 \pm 17.00$ in group A and $123.04 \pm 14.64$ in group B.

Results showed improvements in all shoulder ranges and pain in group A post AROM exer-cises. Shoulder abduction range increased from $96.76 \pm 19.66$ to $112.00 \pm 19.98(\mathrm{p}=0.000)$, in-ternal rotation from $53.71 \pm 7.54$ to $58.38 \pm 8.64(\mathrm{p}=0.000)$, external rotation from $52.76 \pm 8.97$ to $57.90 \pm 9.56(\mathrm{p}=0.000)$ and flexion from $124.57 \pm 17.00$ to $140.00 \pm 18.03$ ( $\mathrm{p}=0.000$ ) which was highly significant. Also NPRS showed a reduction in pain from $7.10 \pm 0.83$ to $4.33 \pm 1.19$ ( $\mathrm{p}=0.000$ ) which was highly significant. GRCS also showed a significant improvement from $-3.00 \pm 0.77$ to $1.38 \pm 1.28$.

Group B who received MET treatment also showed highly significant changes with respect to ROM pain and 
Table 1. Pre Post Variables along with Mean, Standard Deviation, Difference of Mean \& Standard Deviation, Percentage Change, Pre Post Significance and Significance between the Groups Group A, AROM; Group B, MET; NPRS, Numerical Pain Rating Scale; GRC, Global Rate Of Change Scales

\begin{tabular}{|c|c|c|c|c|c|c|c|}
\hline Outcome Measure & & & Mean \pm S.D. & $\begin{array}{c}\text { Mean } \pm \text { S.D of } \\
\text { difference }\end{array}$ & $\begin{array}{c}\text { Change } \\
(\%)\end{array}$ & $\begin{array}{c}\text { Pre-Post } \\
\text { significance }\end{array}$ & $\begin{array}{c}\text { Significance } \\
\text { between the groups }\end{array}$ \\
\hline \multirow[t]{4}{*}{ Abduction } & Group A & Pre & $96.76 \pm 19.66$ & $15.24 \pm 5.078$ & 15.75 & $0.000 \mathrm{HS}$ & 0.026 \\
\hline & & Post & $112.00 \pm 19.98$ & & & & Sig \\
\hline & Group B & Pre & $92.16 \pm 10.61$ & $18.56 \pm 4.71$ & 20.14 & $0.000 \mathrm{HS}$ & \\
\hline & & Post & $110.72 \pm 12.46$ & & & & \\
\hline \multirow[t]{4}{*}{ External-Rotation } & Group A & Pre & $52.76 \pm 8.97$ & $5.14 \pm 2.86$ & 9.75 & $0.000 \mathrm{HS}$ & 0.08 \\
\hline & & Post & $57.90 \pm 9.56$ & & & & \\
\hline & Group B & Pre & $56.88 \pm 6.16$ & $6.96 \pm 3.83$ & 12.24 & $0.000 \mathrm{HS}$ & NS \\
\hline & & Post & $63.84 \pm 7.87$ & & & & \\
\hline \multirow[t]{4}{*}{ Flexion } & Group A & Pre & $124.57 \pm 17.00$ & $15.43 \pm 10.773$ & 12.39 & $0.000 \mathrm{HS}$ & 0.533 \\
\hline & & Post & $140.00 \pm 18.03$ & & & & \\
\hline & Group B & Pre & $123.04 \pm 14.64$ & $16.88 \pm 3.833$ & 13.72 & $0.000 \mathrm{HS}$ & NS \\
\hline & & Post & $139.92 \pm 13.58$ & & & & \\
\hline \multirow[t]{4}{*}{ Internal Rotation } & Group A & Pre & $53.71 \pm 7.54$ & $4.67 \pm 2.033$ & 8.69 & $0.000 \mathrm{HS}$ & 0.261 \\
\hline & & Post & $58.38 \pm 8.64$ & & & & \\
\hline & Group B & Pre & $54.16 \pm 7.25$ & $5.28 \pm 1.621$ & 9.75 & $0.000 \mathrm{HS}$ & NS \\
\hline & & Post & $59.44 \pm 7.67$ & & & & \\
\hline \multirow[t]{4}{*}{ NPRS } & Group A & Pre & $7.10 \pm 0.83$ & $2.76 \pm 0.831$ & 38.93 & $0.000 \mathrm{HS}$ & 0.282 \\
\hline & & Post & $4.33 \pm 1.19$ & & & & \\
\hline & Group B & Pre & $7.24 \pm 0.59$ & $3.04 \pm 0.889$ & 41.99 & $0.000 \mathrm{HS}$ & NS \\
\hline & & Post & $4.20 \pm 1.08$ & & & & \\
\hline \multirow[t]{4}{*}{ GRC } & Group A & Pre & $-3.00 \pm 0.77$ & $-4.38 \pm 1.2$ & 146.03 & $0.000 \mathrm{HS}$ & $0.000 \mathrm{HS}$ \\
\hline & & Post & $1.38 \pm 1.28$ & & & & \\
\hline & Group B & Pre & $-3.60 \pm 0.50$ & $-6.96 \pm 0.89$ & 193.33 & $0.000 \mathrm{HS}$ & \\
\hline & & Post & $-3.36 \pm 0.64$ & & & & \\
\hline
\end{tabular}

GRCS.The abduction range improved from $92.16 \pm 10.61$ to $110.72 \pm 12.46(\mathrm{p}=0.000)$, internal rotation from $54.16 \pm 7.25$ to $59.44 \pm 7.67(\mathrm{p}=0.000)$, external rotation from $56.88 \pm 6.16$ to $63.84 \pm 7.87(\mathrm{p}=0.000)$, flexion from $123.04 \pm 14.64$ to $139.92 \pm 13.58(\mathrm{p}=0.000)$, NPRS from $7.24 \pm 0.59$ to $4.20 \pm 1.08(\mathrm{p}=0.000)$ and GRC from -3.60 \pm 0.50 to $3.36 \pm 0.64$.

Between group analysis was done to compare the improvements between group A and group B. It was found that group B who received MET treatment showed significant improvements when compared to group A in Abduction ROM ( $p=0.026)$, NPRS $(p=0.282)$ and a highlyi sig-nificant improvement in GRC scores $(\mathrm{p}=0.000)$ when compared to Group A (Table 1$)$.

\section{Discussion}

This study aimed at comparing the effectiveness of METs with AROM exercises in subjects who underwent MRND. All subjects recruited for this study showed a significant improve-ment in shoulder range of motion and also experienced a reduction in pain and felt clinically better after a treatment of 10 days.

Significant improvements were found in shoulder range of motion and reduced pain post 10 days intervention period in subjects allocated to AROM (group A) and MET groups(group B). AROM exercises cause joint distraction as well as oscillations which results in decreased pain, early mobilization of joint and increased flow of nutrients to the joint space (Baggi et al., 2014 ; Ellsworth et al., 2006). Group B demonstrated significant improvements in shoul-der ranges and decreased intensity of pain compared to Group A. This could be due to the analgesic effect of MET allowing the subjects to reach greater range of motion while provid-ing greater stretch tolerance (Phadke et al., 2016; Moore et al., 2011; Gary and Christian, 2010). Our findings are similar to the study done by Narayan et al., (2014) which stated that MET exercises can improve the mobility of joints as it causes restoration of normal length- tension relationship of the muscles which in turn undergo adaptive or protective shortening due to intrinsic or extrinsic factors. Improvement in range can also be due to the reflex relaxation of the agonist group of muscles after an isometric contraction. This reflex relaxation is suggested to be mediated by the Golgi tendon organ and its inhibitory effect on the alpha-motor neuron pool. Reciprocal inhibition from the antagonist muscle contractions could also have an effect on improving the mobility of the joint (Chaitow, 2006 ; Magnusson et al., 1996) The changes in the muscle extensibility and joint range of motion could be related to the mechanisms which promote hypoalgesia and an increase in stretch tolerance 


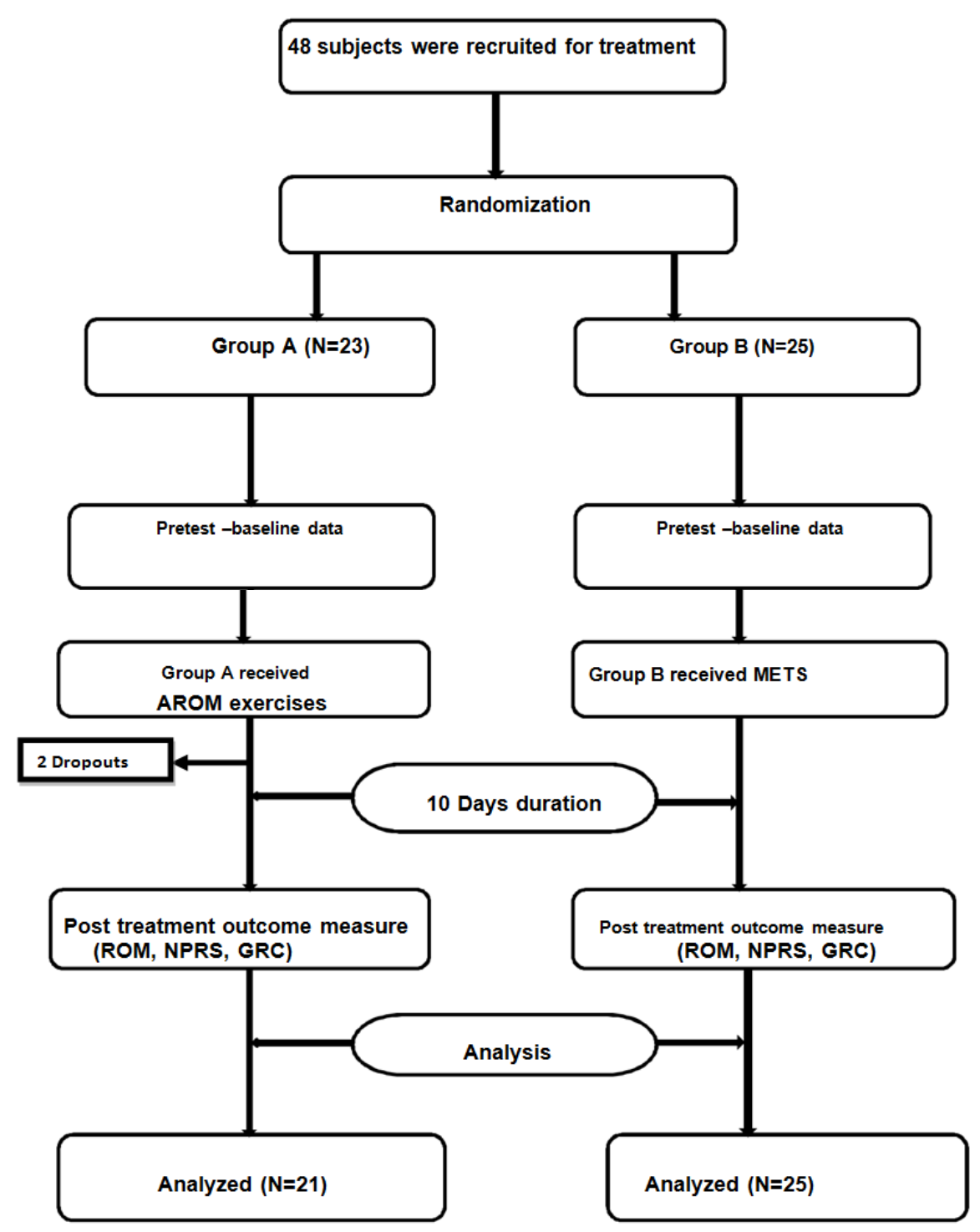

Figure 1. CONSORT Flow Chart

of the subjects. However, in the current study we found that range of motion in abduction significantly had better gains in group B than in group A. MET have shown to improve muscle extensibility and also cause an increase in muscle strength with isometric contractions. The subjects in group B may have gained strength in abductors and this could be the reason for increase in abduction range of motion in group B. Also, there was an improvement in shoulder function in Group B which can be attributed to one of the effects of METs (Chaitow, 2006; Wilson et al., 2003; Ballantyne et al., 2003).

Subjects of both the groups were on analgesics, on an average 4-5 days postoperatively, but the decrease in pain cannot solely be attributed to effects of the analgesics. Intensity of Pain (NPRS) decreased post intervention significantly in Group A and B. The exact physiology be-hind the therapeutic effects of MET on pain reduction is still not clear but it is suggested that it might be due to the involvement of various biomechanical and neurological mechanisms, such as altered proprioception, hypoalgesia, changes in tissue fluid, motor programming and motor control (Gary and Christian, 2010).

Between group analysis evaluated using Global rating change scores demonstrated an overall clinical progress in both the groups when compared to their baseline values .Group B demonstrated significantly better improvements than group A, this could be attributed to the fact that GRC scores are well correlated with pain, disability and Quality of life. Reduction in pain and improvement in range of motion in MET group could have lead to better outcomes (Kamper et al., 2009).

Significant improvements were also found in shoulder range of motion post 10 days inter-vention period in subjects allocated to AROM group (group A). AROM exercises cause joint distraction as well as oscillations which results in decreased pain, early mobilization of joint and increased flow of nutrients to the joint space (Baggi et al., 2014; Ellsworth et al., 2006).

In conclusion, the present study showed that Muscle energy technique (MET) and active range of motion (AROM) exercises are effective in improving shoulder range of motion, reducing pain and improved GRCS. Between group analyses demonstrates MET exercises to have better clinical outcomes in improving abduction range of motion, decreasing pain and clinically better global rating scorescompared to AROM exercises. 
Further studies with longterm followup and larger sample size could give better understand-ing.

\section{Acknowledgements}

This study was approved by the Institutional Ethical Committee of Father Muller Charitable Institutions (Approval number 5107/17) and is a part of an approved post graduate thesis. All the authors have equally contributed to the work. We have no conflicts of interest.

Clinical Trial Registration was done at Clinical Trial Registry of Government of India. CTRI TRIAL NUMBER: REF/2017/02/013459

\section{References}

Baggi F, Santoro L, Grosso E (2014). Motor and functional recovery after neck dissection: comparison of two early physical rehabilitation programmes. Acta Otorhinolaryngol Ital, 34, 230- 56.

Ballantyne F, Fryer G, McLaughlin P (2003). The effect of muscle energy technique on hamstring extensibility: The mechanism of altered flexibility. J Osteopath Med, 6, 59-63.

Bathia K, Eapen C, Zulfeequer CP (2016). Effectiveness of muscle energy technique and passive stretching on posterior shoulder tightness in cricket bowlers-a randomized clini-cal trial. Int J Sci Res, 5, 354-60.

Chaitow L (2006). Muscle energy techniques. An Introduction to Muscle energy techniques. Elsevier Health Sciences. Toronto, pp 8-9.

Chauhan NS, Samuel SR, Meenar N, Saxena PP, Keogh JW(2020). Sarcopenia in male pa-tients with head and neck cancer receiving chemoradiotherapy: A longitudinal pilot study. PEER J, 8, e8617.

Cheng PT, Hao SP, Lin YH, Yeh AR(2000). Objective comparison of shoulder dysfunction after three neck dissection techniques. Ann Otol Rhinol Laryngol, 109, 761-6.

Chepeha DB, Taylor RJ, Chepeha JC (2002). Functional assessment using constant's shoulder scale after modified radical and selective neck dissection. Head Neck, 24, 432-6.

Ellsworth AA, Mullaney M, Tyler TF, McHugh M, Nicholas S (2006). Electromyography of selected shoulder musculature during un-weighted and weighted pendulum exercises. NAM J Sports Phys Ther, 1, 73.

Ewing MR, Martin H (1952). Disability following Radical Neck Dissection; An assessment based on the postoperative evaluation of 100 patients. Cancer, 5, 873-83.

Fryer G, Fossum C(2010). Therapeutic mechanisms underlying muscle energy approaches. In: Tension-Type and Cervicogenic Headache: Pathophysiology, Diagnosis, and Management. Jones and Bartlett Publishers. Sudbury, pp 221-9.

Gane EM, Michaleff ZA, Cottrell MA, et al (2017). Prevalence, incidence, and risk factors for shoulder and neck dysfunction after neck dissection: A systematic review. Eur J Surg Oncol, 43, 1199-218.

Ginn K, Cohen M (2005). Exercise therapy for shoulder pain aimed at restoring neuro-muscular control: A randomized comparative clinical trial. J Rehabil Med, 37, 115-22.

Guru K, Manoor UK, Supe SS (2012). A comprehensive review of head and neck cancer rehabilitation: Physical therapy perspectives. Indian J Palliat Care, 18, 87-97.

Kamper, SJ, Maher CG, Mackay G (2009). Global rating of change scales: a review of strengths and weaknesses and considerations for design. J Man Manip Ther, 17, 163-70.

Luan X, Mao C, Yu G et al (2006). The impacts of various types of neck dissection on post-operative shoulder function for patients with oral squamous cell carcinoma. Zhonghua Kau Qiang Yi Xue Za Zhi, 41, 287-90.

Lauchlan DT, Mc Caul JA, Mc Carron T, et al (2011). An exploratory trial of preventative re-habilitation on shoulder disability and quality of life in patients following neck dissection surgery. Eur J Cancer Care, 20, 113-22.

MacComb WS (1968). Mortality from radical neck dissection. Am J Surg, 115, 352-4.

Magnusson SP, Simonsen EB, Aagaard P (1996). Mechanical and physical responses to stretching with and without preisometric contraction in human skeletal muscle. Arch Phys Med Rehabil, 77, 373-8.

Moore SD, Laudner KG, Mcloda TA, Shaffer MA (2011). The immediate effects of muscle energy technique on posterior shoulder tightness: a randomised controlled trial, 41, 400-7.

Narayan A, Jagga V (2014). Efficacy of muscle energy technique on functional ability of shoulder in adhesive capsulitis. J Exersc Sci Physiother, 10, 72-6.

Phadke A, Bedekar N, Shyam A, Sancheti P (2016). Effect of muscle energy technique and static stretching on pain and functional disability in patients with mechanical neck pain: A randomized controlled trial. Hong Kong Physiother J, 35, 5-11.

Reeve J, Stiller K, Nicol K, et al(2010). A postoperative shoulder exercise program improves function and decreases pain following open thoracotomy: A randomised trial. $J$ Physiother, 56, 245-52.

Robbins KT, Medina JE, Wolfe GT (1991). Standardizing neck dissection terminology. Offi-cial report of the Academy's Committee for Head and Neck Surgery and Oncology. Arch Otolaryngol Head Neck Surg, 117, 601-5.

Van Wilgen CP, Dijkstra PU, Van Der Laan B F AM, Plukker JT, Roodenburg JLN(2003). Shoulder complaints after neck dissection; Is the spinal accessory nerve involved?. Br J Oral Maxillofac SurG, 41, 7-11.

Van Wilgen CP, Dijkstra PU, van der Laan BF, Plukker JT, Roodenburg JL (2004). Shoulder complaints after nerve sparing neck dissections. Int J Oral Maxillofac Surg, 33, 253-7.

Wilson E, Payton O, Donegan-Shoaf L, Dec K (2003). Muscle energy technique in patients with acute low back pain: A pilot clinical trial. J Orthop Sports Phys Ther, 33, 502-12.

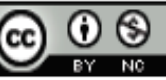

This work is licensed under a Creative Commons AttributionNon Commercial 4.0 International License. 